\title{
Association of miR-125b, miR-17 and let-7c Dysregulations With Response to Anti-epidermal Growth Factor Receptor Monoclonal Antibodies in Patients With Metastatic Colorectal Cancer
}

\author{
ONDREJ FIALA ${ }^{1,2}$, ONDREJ SOREJS ${ }^{1,2}$, PETR HOSEK $^{2}$, VACLAV LISKA $^{2,3}$, ONDREJ VYCITAL $^{3}$, JAN BRUHA $^{3}$, \\ RADEK KUCERA $^{4}$, ONDREJ TOPOLCAN ${ }^{4}$, JINDRICH FINEK $^{1}$, DIANA MACECKOVA ${ }^{2}$ and PAVEL PITULE ${ }^{2}$ \\ ${ }^{1}$ Department of Oncology and Radiotherapeutics, Faculty of Medicine and University Hospital in Pilsen, \\ Charles University, Pilsen, Czech Republic; \\ ${ }^{2}$ Biomedical Center, Faculty of Medicine in Pilsen, Charles University, Pilsen, Czech Republic; \\ ${ }^{3}$ Department of Surgery, Faculty of Medicine and University Hospital in Pilsen, \\ Charles University, Pilsen, Czech Republic; \\ ${ }^{4}$ Department of Immunochemistry Diagnostics, Faculty of Medicine and University Hospital in Pilsen, \\ Charles University, Pilsen, Czech Republic
}

\begin{abstract}
Background/Aim: MicroRNAs (miRs) play an important role in the regulation of cancer-related processes and are promising candidates for cancer biomarkers. The aim of the study was to evaluate the association of response to anti-EGFR monoclonal antibodies ( $m A b s$ ) with selected miR expression profiles, including miR-125b, let-7c, miR$99 a$, miR-17, miR-143 and miR-145 in metastatic colorectal cancer (mCRC) patients. Patients and Methods: This retrospective study included 46 patients with $m C R C$ harbouring wild-type RAS gene treated with cetuximab or panitumumab combined with chemotherapy in first-or second-line therapy. The miR expression was assessed using qRT-PCR. Results: Down-regulation of miR-125b and let-7c and up-regulation of miR-17 were found in the tumour tissue $(p=0.0226, p=0.0040, p<0.0001)$. Objective response rate (ORR) was associated with up-regulation of miR-125b ( $p=0.0005)$. Disease control rate (DCR) was associated with up-regulation of miR-125b and let-7c $(p=0.0383$ and $p=0.0255)$ and down-regulation of $m i R-17$
\end{abstract}

This article is freely accessible online.

Correspondence to: Ondrej Fiala, MD, Ph.D., Department of Oncology and Radiotherapy, Faculty of Medicine and University Hospital Pilsen, Charles University Prague, alej Svobody 80, CZ30460 Pilsen, Czech Republic. Tel: +42 0728655488, e-mail: fiala.o@centrum.cz

Key Words: Colorectal cancer, cetuximab, panitumumab, chemotherapy, microRNA, miR-125b, miR-17, let-7c. $(p=0.0464) . \quad M i R-125 b$ showed correlation with progression-free and overall survival ( $p=0.055$ and $p=0.006)$. Conclusion: The results show that up-regulation of miR-125b is associated with higher ORR and DCR and longer survival; let-7c up-regulation and miR-17 downregulation are associated with higher DCR in $m C R C$ patients treated with anti-EGFR mAbs.

Colorectal cancer (CRC) is one of the most common malignancies whose incidence has been increasing in developed countries (1). Clinical trials have provided evidence for the efficacy and safety of monoclonal antibodies (mAbs) targeting the epidermal growth factor receptor (EGFR) represented by cetuximab and panitumumab, in the treatment of patients with metastatic CRC (mCRC). Both agents have been widely used in $\mathrm{mCRC}$ patients with tumours harbouring a wild-type $R A S$ gene. Despite the standard use of $R A S$ gene mutations as effective biomarkers predictive of resistance to anti-EGFR mAbs, there is a large proportion of patients with tumours harbouring a wild-type $R A S$ gene who obtain poor benefit from this systemic treatment (2-9). There is therefore an urgent need for novel complementary predictive and prognostic biomarkers.

MicroRNAs (miRs) are small non-coding RNAs, consisting of approximately 18-25 nucleotides that play an important role in the regulation of target gene expression. MiRs are involved in the regulation of key cancer-related processes including proliferation, differentiation, apoptosis, cell adhesion and angiogenesis (10). The role of miRs as biomarkers useful in diagnostics or prognostic estimation in cancer patients has been extensively studied. 
The aim of the present study was to evaluate the association of a number of selected miR expression profiles with response to anti-EGFR mAbs in mCRC patients harbouring a wild-type $R A S$ gene. The selected miRs included: miR-125b, let-7c, miR-99a, miR-17, miR-143 and miR-145.

\section{Patients and Methods}

Patients and treatment. The study included 46 patients with histologically confirmed mCRC who were treated with a combination of anti-EGFR mAbs (cetuximab or panitumumab) and chemotherapy as first- or second-line treatment between the years 2010 and 2019 at the Department of Oncology and Radiotherapeutics, Medical School and University Hospital in Pilsen, Czech Republic. The chemotherapy backbone consisted of the following regimens: fluorouracil and leucovorin in combination with oxaliplatin (FOLFOX), or with irinotecan (FOLFIRI). Panitumumab (Vectibix, Amgen Inc., Thousand Oaks, CA, USA) was administered in combination with chemotherapy, or as a single agent, in the standard approved dose $(6.0 \mathrm{mg} / \mathrm{kg}$ every 14 days $)$. Cetuximab (Erbitux, Merck \& Co., Kenilworth, NJ, USA) was administered in combination with chemotherapy, or as a single agent, in the standard approved dose (initial dose $400 \mathrm{mg} / \mathrm{m}^{2}$, further doses $250 \mathrm{mg} / \mathrm{m}^{2}$ every 7 days). None of the patients had previously received anti-EGFR mAbs.

Clinical monitoring. Clinical data were obtained retrospectively from the hospital information system. Physical examination and routine laboratory tests were performed every two weeks; a computed tomography $(\mathrm{CT})$ or positron emission tomography (PET)-CT was performed every three months of the treatment. The objective tumour response was assessed by an experienced radiologist using Response Evaluation Criteria in Solid Tumours (RECIST) version 1.1 in terms of: complete response (CR), partial response (PR), stable disease (SD) and progressive disease (PD); objective response rate (ORR) included patients achieving $C R$ and PR; disease control rate (DCR) included those achieving CR, PR and SD (11).

The study protocol was approved by the independent Ethics Committee of the Medical School and University Hospital in Pilsen and complied with the International Ethical Guidelines for Biomedical Research Involving Human Subjects, Good Clinical Practice guidelines, the Declaration of Helsinki, and local laws.

Assessment of miR expression. The total RNA from tumour tissue samples and macroscopically healthy adjacent non-tumour colon mucosa was isolated using TRI Reagent ${ }^{\circledR}$ RT (MRC, Cincinnati, $\mathrm{OH}, \mathrm{USA})$, following the manufacturer's protocol. The total RNA concentration was measured by Qubit RNA HS Assay Kit (ThermoFisher Scientific, Waltham, MA, USA) and all samples were diluted to $2 \mathrm{ng} / \mu \mathrm{l}$ before reverse transcription. For the assessment of miR expression, gene-specific TaqMan assays (ThermoFisher Scientific) were used. The targets of the analysis were: hsa-miR-125b-5p (assay ID 000449), hsa-miR-17-5p (assay ID 002308), hsa-let-7c-5p (assay ID 000379), hsa-miR-145-5p (assay ID 002278), hsa-miR-143-3p (assay ID 002249) and hsamiR-99a-5p (assay ID 000435). hsa-miR-16-5p (assay ID 000391) and hsa-miR-345-5p (assay ID 002186) were chosen as reference genes based on our previous experience (12). TaqMan ${ }^{\circledR}$ MicroRNA Reverse Transcription Kit (ThermoFisher Scientific) was used for the separate reverse transcription of individual genes using target specific primers from corresponding TaqMan Assays. The relative expression of microRNAs was measured in duplicates in $10 \mu \mathrm{l}$ reactions using the CFX96 real-time PCR system (Bio-Rad, Hercules, CA, USA) with TaqMan ${ }^{\circledR}$ Universal Master Mix II, with UNG (ThermoFisher Scientific). The following amplification parameters were used: $2 \mathrm{~min}$ at $50^{\circ} \mathrm{C}$ and $10 \mathrm{~min}$ at $95^{\circ} \mathrm{C}$, followed by 45 cycles of $15 \mathrm{~s}$ at $95^{\circ} \mathrm{C}$ and $1 \mathrm{~min}$ at $60^{\circ} \mathrm{C}$. All reactions were tested for nonspecific signals.

Statistical analysis. Standard frequency tables and descriptive statistics were used to characterize the patient group. Changes of miR expression levels in tumour tissue (relative to adjacent nontumour tissue) were expressed in $-\Delta \Delta \mathrm{Ct}$ values and because of their mostly normal distribution (as reviewed in histograms and using a Shapiro-Wilk test) were analysed using parametric methods. Expression of the miR-143/miR-145 cluster was determined as an arithmetic mean of $-\Delta \Delta C_{t}$ values for miR-143 and miR-145, and was analysed analogically to the other miR expression levels. A one sample $t$-test against a zero reference was used to test for significant up- or down-regulation. Differences in the level of change in miR expression between pairs of treatment response groups (objective response (CR or PR) achieved/not achieved, and disease control achieved (CR, PR or SD)/not achieved) were tested for significance using a two-sample $t$-test.

Progression-free survival (PFS) was determined from the date of anti-EGFR therapy initiation until the date of first documented progression, or death. Overall survival (OS) was determined from the date of anti-EGFR therapy initiation until the date of death, regardless of its cause. Patients who had not progressed or died were censored at the date of their last follow-up. Median survival times were calculated from the Kaplan-Meier estimates of survival functions using linear interpolation between the nearest complete observations. The median follow-up was estimated from OS data using the inverse Kaplan-Meier method. Significance of associations between miR expression change and survival times was assessed using a univariable Cox proportional hazards model. In order to visualize these associations and detect possible non-proportional ones, significant or borderline results were reviewed using automated stratification. In this procedure, a threshold (cut-off) miR expression change value was determined by an automated optimization process finding the threshold that provided the lowest Cox-Mantel $p$-value in the two-sample Kaplan-Meier analysis, which was finally verified using a Gehan-Wilcoxon test.

All reported $p$-values are two-tailed and the level of statistical significance was set at $\alpha=0.05$. Statistical processing and testing was performed in a STATISTICA data analysis software system (StatSoft, Inc.2013, Version 12, www.statsoft.com) and Matlab (2019b, MathWorks Inc., Natick, MA, USA).

\section{Results}

Patient characteristics. The study included $46 \mathrm{mCRC}$ patients. The median age at anti-EGFR therapy initiation was 63.6 (range $=37.3-82.5)$. Thirty-four $(73.9 \%)$ patients were males, $30(65.2 \%)$ had the primary tumour localized in the colon, 27 (58.7\%) had synchronous metastatic disease, 36 $(78.3 \%)$ received the anti-EGFR mAbs-containing regimen 
Table I. Baseline characteristics of included patients.

\begin{tabular}{lc}
\hline Characteristic & $\mathrm{n}(\%)$ \\
\hline Gender & \\
Female & $12(26.1)$ \\
Male & $34(73.9)$ \\
Age & \\
Median [range] & $63.6[37.3-82.5]$ \\
Localization of primary tumour & \\
Rectum & $16(34.8)$ \\
Colon & $30(65.2)$ \\
Sidedness of primary tumour & \\
Left & $37(80.4)$ \\
Right & $7(15.2)$ \\
Transversum & $2(4.4)$ \\
Primary tumour grade & \\
G1 & $5(10.9)$ \\
G2 & $35(76.1)$ \\
G3 & $5(10.8)$ \\
Unknown & $1(2.2)$ \\
TNM stage at diagnosis & \\
T1 & $1(2.2)$ \\
T2 & $1(2.2)$ \\
T3 & $40(86.8)$ \\
T4 & $2(4.4)$ \\
TX & $2(4.4)$ \\
N0 11 & $8(17.4)$ \\
N2 & $15(32.6)$ \\
NX & $22(47.8)$ \\
M1 & $1(2.2)$ \\
M0 & $27(58.7)$ \\
Fine of therapy & $19(41.3)$ \\
Second & \\
Anti-EGFR antibody & $36(78.3)$ \\
Cetuximab & $10(21.7)$ \\
Panitumumab & \\
FOLFOX & $21(45.6)$ \\
FOLFIRI & $25(54.4)$ \\
& \\
& $27(58.7)$ \\
(n) & $19(41.3)$ \\
\hline
\end{tabular}

as first-line therapy. Twenty-five $(54.3 \%)$ patients were treated with panitumumab and $21(45.7 \%)$ patients were treated with cetuximab. The baseline patient characteristics are summarized in Table I. The median PFS of the whole cohort was 8.9 months (95\% CI=7.0-12.26) and the median OS was 26.4 months (20.1-39.2). Median follow-up time was 61.7 months. ORR and DCR in the whole cohort were $54.3 \%$ (95\% CI=39.9-68.1\%) and 78.3\% (63.9-88.1\%), respectively.

Expression of miR-125b, let-7c, miR-99a, miR-17, miR-143 and $\mathrm{miR}-145$ in the tumour tissue. Low tumour expression of miR-125b and let-7c in comparison with adjacent nontumour tissue was found in 27 out of $42(64.3 \%)$ and 30 out of $43(69.8 \%)$ patients, respectively $(p=0.0226$ and

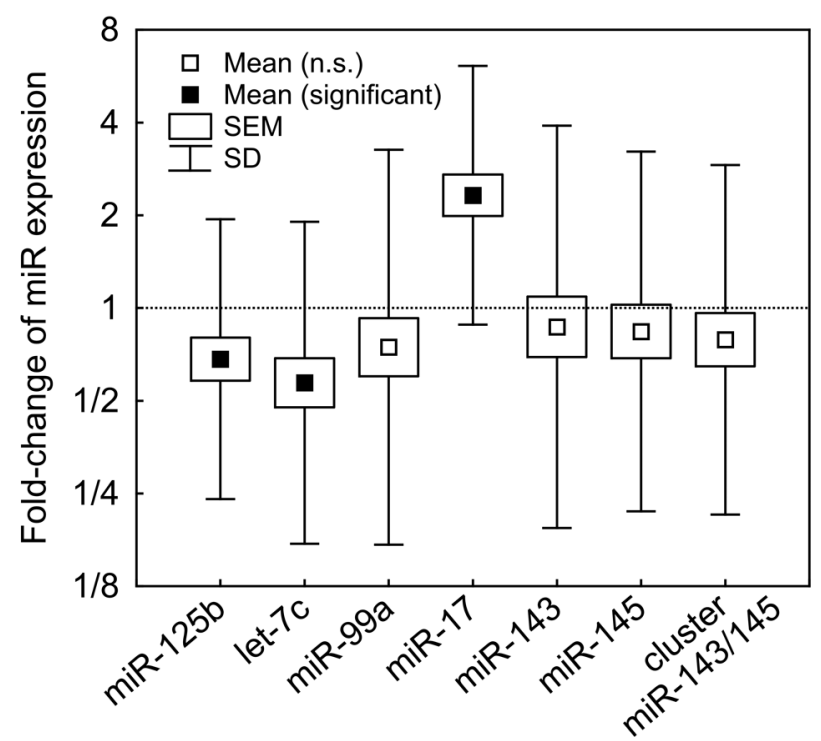

Figure 1. The differential expression levels of assessed miRs between tumour and adjacent non-tumour tissues.

$p=0.0040$, respectively). High tumour expression of miR-17 in comparison to adjacent non-tumour tissue was observed in 33 out of $39(84.6 \%)$ patients $(p<0.0001)$. There were no significant differences in the expression of miR-99a, miR143, miR-145 or the whole miR-143/miR-145 cluster between tumour and adjacent non-tumour tissue $(p=0.1851$, $p=0.5376, p=0.3862$ and $p=0.2392$, respectively). The differential expression levels of assessed miRs are shown in Figure 1.

Association of miR-125b, let-7c, miR-99a, miR-17, miR-143 and miR-145 with response to anti-EGFR mAbs. ORR $(\mathrm{CR}+\mathrm{PR})$ was significantly associated with up-regulation of miR-125b $(p=0.0005)$ (Figure 2A), while the relative expression levels of let-7c, miR-99a, miR-17, miR-143, miR-145 and the whole miR-143/miR-145 cluster were not associated with ORR $(p=0.1418, p=0.1565, p=0.6419$, $p=0.9015, p=0.7799$ and $p=0.8553$, respectively). DCR $(\mathrm{CR}+\mathrm{PR}+\mathrm{SD})$ was significantly associated with upregulation of miR-125b and let-7c $(p=0.0383$ and $p=0.0255$, respectively) and down-regulation of miR-17 $(p=0.0464)$ (Figure 2B, C and D), while the relative expression levels of miR-99a, miR-143, miR-145 and the whole miR-143/miR145 cluster were not associated with DCR $(p=0.1211$, $p=0.9706, p=0.7399$ and $p=0.8580$, respectively).

Association of miR-125b, let-7c, miR-99a, miR-17, miR-143 and miR-145 with PFS and OS. The results of the univariable Cox proportional hazards model suggested a possible association with PFS and OS only for miR-125b 
A

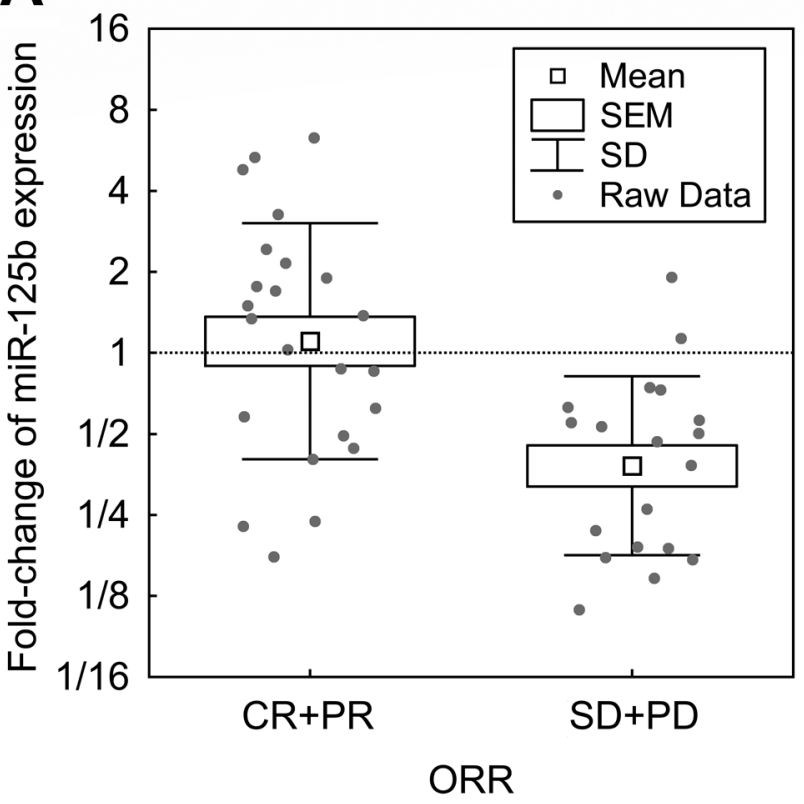

C

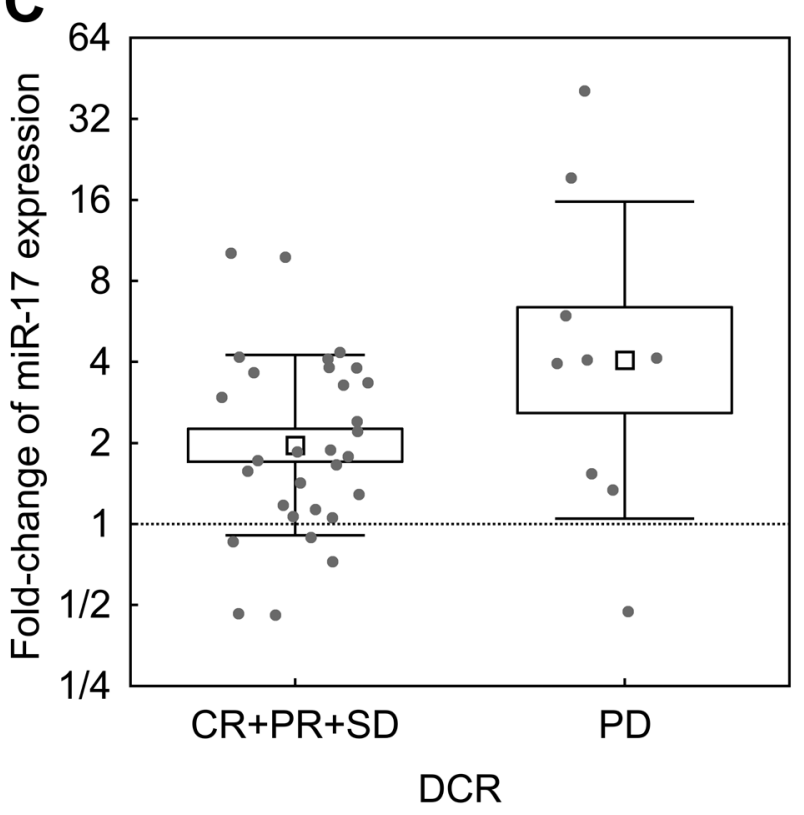

B

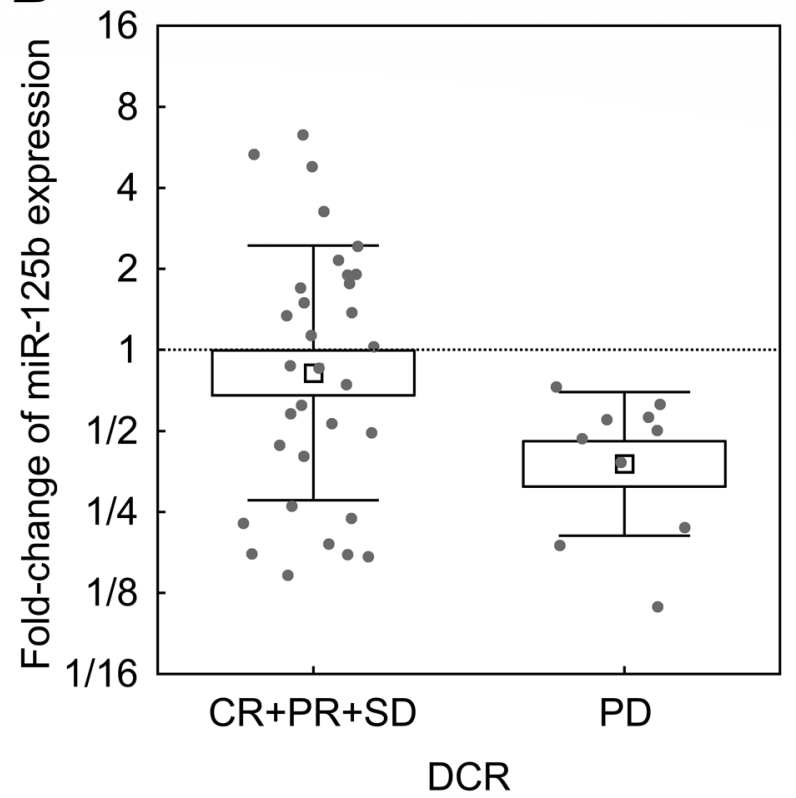

D

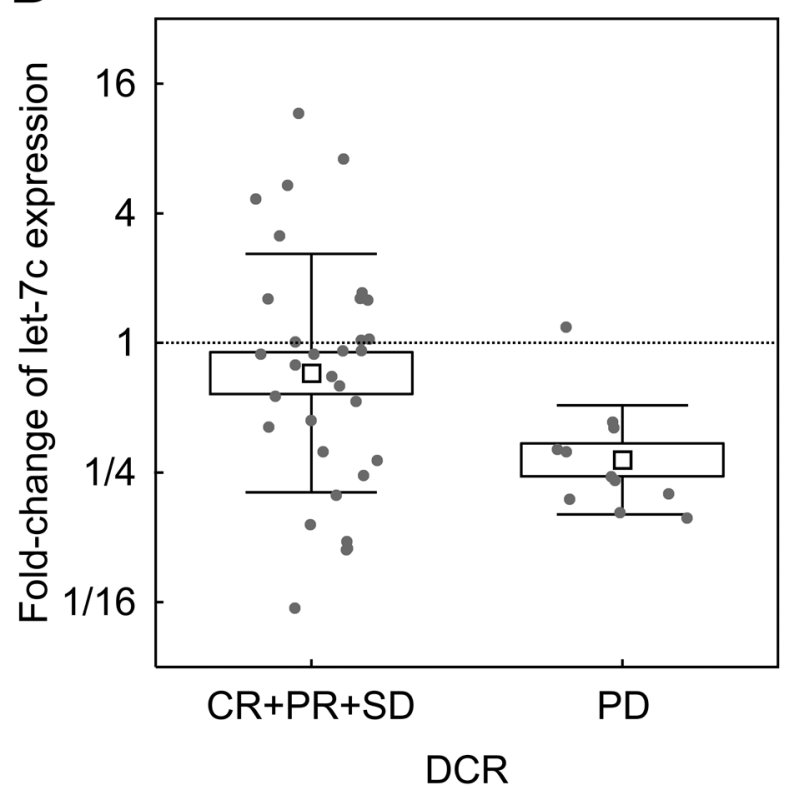

Figure 2. The association of differential expression levels of miR-125b with objective response (A), miR-125b with disease control (B), miR-17 with disease control $(C)$ and let-7c with disease control $(D)$.

dysregulation, however, without confirming statistical significance $[p=0.1389$ with hazard rate $(\mathrm{HR})$ of 0.849 per unit of $-\Delta \Delta C_{t}$ value for PFS, and $p=0.0680$ with HR of 0.771 for OS]. The remaining miRs showed no indication of being associated with PFS or OS ( $p>0.2$ for all). After further investigation using automated optimization of stratification threshold, miR-125b showed strong separation between long- and short-surviving patients at a threshold value of -2.17 (i.e. 4.5 -fold decrease of miR-125b levels in tumour tissue) (Figure 3). Contrastingly, its performance for other threshold values was mediocre.

\section{Discussion}

The treatment of mCRC has been markedly changing in recent years with the introduction of targeted therapies 


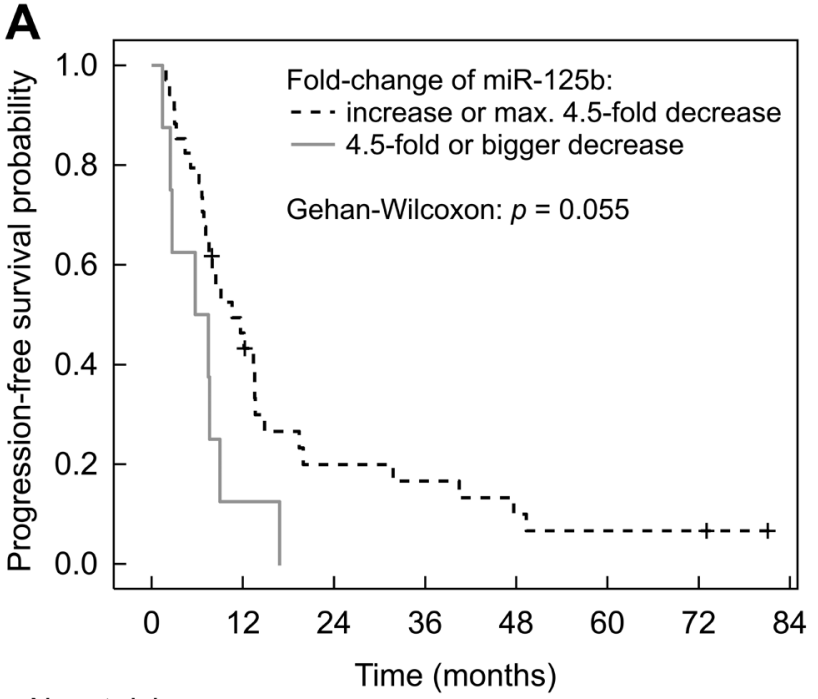

No. at risk:

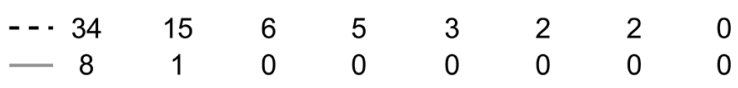

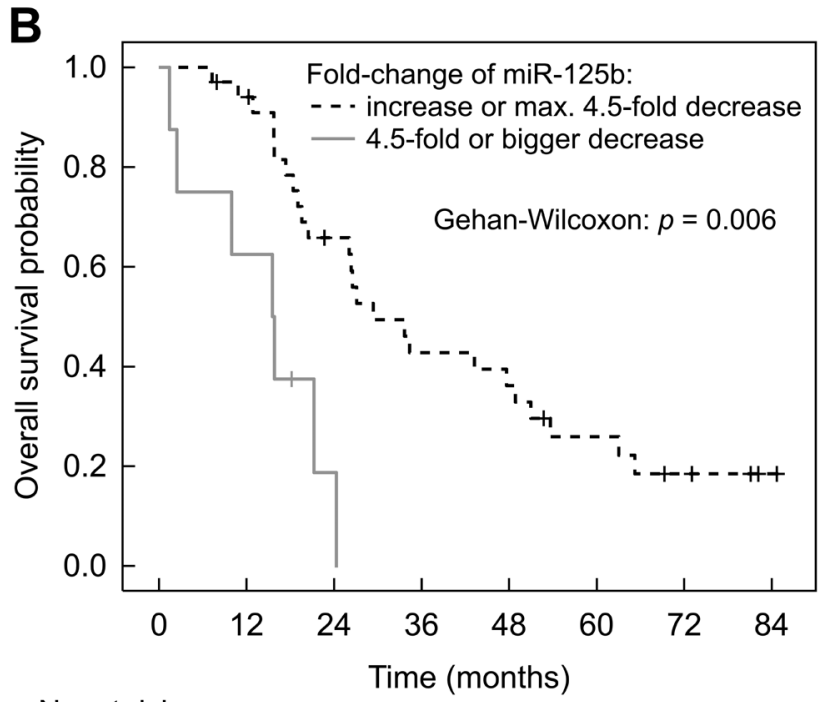

No. at risk:

$\begin{array}{cccccccc}-34 & 31 & 20 & 13 & 11 & 7 & 4 & 1 \\ -8 & 5 & 1 & 0 & 0 & 0 & 0 & 0\end{array}$

Figure 3. Progression-free survival (PFS) (A) and overall survival (OS) (B) according to miR-125b differential expression levels using automated optimization of stratification threshold value of 4.5-fold decrease of miR-125b levels in tumour tissue.

leading to improvements in patient survival. Prognostic and predictive biomarkers play a crucial role in the management of cancer as they help clinicians use the optimal treatment strategy for each individual patient. Our data suggest that down-regulation of miR-125b and let-7c, as well as upregulation of miR-17, are associated with a poor response to systemic therapy based on anti-EGFR mAbs. We, therefore, suggest that these miRs are promising candidates for predictive biomarkers.

In the field of mCRC, RAS gene mutations, including $K R A S$ and NRAS mutations, represent well-established predictive biomarkers. Nevertheless, a large proportion of mCRC patients with tumours harbouring wild-type $R A S$ gene derive poor benefit from systemic treatment based on antiEGFR mAbs.

The basic function of miRs is regulation of expression of target protein coding genes by binding to their specific messenger RNA (mRNA), leading to mRNA degradation and subsequently to inhibition of protein translation (13). Each miR achieves functional specificity by targeting a core network of genes involved in multiple signaling pathways (14). Therefore, miRs may act as oncogenes or tumour suppressor genes and their dysregulation (i.e. up-regulation or down-regulation) is common in cancer. In the field of cancer treatment, miRs can serve as potential targets for the systemic therapy and also they are regarded as promising candidates for novel cancer biomarkers (15-17). As diagnostic biomarkers, circulating and urinary miRs have the potential to be non-invasive and cheap diagnostic tools. In terms of prognostication, there is a hope that miR signatures, eventually combined with other genetic or clinical factors, will be able to more precisely stage and subtype cancers according to the prognosis of patients and/or response to the systemic therapies. In the future, they could be used as valuable predictive biomarkers playing a key role in the treatment individualisation within the concept of personalised oncology.

In the present study, we focused on the association of the dysregulations of miR-125b, let-7c, miR-99a, miR-17, miR143 and miR-145 with the outcome of mCRC patients harbouring a wild-type RAS gene who had been treated with anti-EGFR mAbs combined with standard chemotherapy as first- or second-line therapy. The selection of investigated miRs was based on a literature search.

MiR-125b is a member of the miR-125 family, which is known to play a crucial role in many cancer-related processes including proliferation, cell differentiation and apoptosis (18). The targeting of multiple genes involved in the process of initiation and progression of cancer by miR$125 \mathrm{~b}$ has been described in the literature and miR-125b dysregulation is commonly seen in many cancers. Interestingly, miR-125b targets both tumour suppressor genes and oncogenes, leading to its up- or down-regulation having distinct effects, which seem to be dependent on specific tumour type (18). Down-regulation of miR-125b has been described in breast cancer, non-small-cell lung cancer, 
oesophageal squamous cell cancer, bladder cancer, thyroid cancer, melanoma, hepatocellular cancer, ovarian cancer, osteosarcoma, chondrosarcoma, and CRC. Its up-regulation has been reported in retinoblastoma, nasopharyngeal cancer, glioblastoma and certain leukemias $(18,19)$. Among others, miR-125b targets the p53 tumour suppressor gene: a key regulator of apoptosis (20). Additionally, it has been demonstrated that miR-125b targets several other apoptosis regulators, such as PUMA and BAK1 as well as cell cycle regulators, including cyclin $\mathrm{C}$ (20). Consequently, in tumours characterised by miR-125b up-regulation, miR-125b predominantly acts as an oncogene, leading to the blocking of apoptosis and causing stimulation of proliferation. On the other hand, miR-125b also targets genes encoding human epidermal growth factor receptor (HER) 2 and 3, which represent important oncogenic signalling molecules that are up-regulated in several cancers, typically in breast cancer (21). In these tumours, miR-125b down-regulation causes increased HER $2 / 3$ signalling involved in carcinogenesis and cancer progression and miR-125b may predominantly act as a tumour suppressor. The role of miR-125b dysregulation in CRC is poorly understood, and its association with the outcome of patients treated with anti-EGFR targeted therapy is particularly unclear. In the present study, we observed significant down-regulation of miR-125b in the CRC tissue compared to the adjacent non-tumour tissue. This is in agreement with a study previously reported by Chen and $\mathrm{Xu}$, who further suggested that DNA hypermethylation may be involved in down-regulation of miR-125a and miR-125b in CRC (22). We found a significantly lower ORR and DCR as well as a shorter PFS and OS for patients with miR-125b down-regulation. These results are in line with a previous study conducted by Capuzzo et al. that included 183 mCRC patients from two independent cohorts treated with antiEGFR mAbs (23). In our study, however, after taking into account the limited sample size, the significant differences in PFS and OS were obtained following an optimization process that found the threshold for the lowest $\mathrm{p}$-value in a Kaplan-Meier analysis. This analysis showed a strong separation between long- and short-surviving patients using the optimised threshold value. Contrastingly, the results for other threshold values were mediocre, suggesting that its relationship to survival is nonlinear.

Let-7c is a member of the let-7 family including let-7a, let-7b, let-7c, let-7d, let-7e, let-7f, let-7g, let-7i, miR-98 and miR-202 (24). Their main role is regulation of cell differentiation and proliferation, which they achieve by targeting a variety of signalling pathways (25). For instance, the let-7 family negatively regulates the expression of $R A S$ as well as other oncogenes such as MYC, IGF1 and HMGA2, which represent critical regulators for the growth of CRC (26-28). Thus, the let-7 family members are widely viewed as tumour suppressors down-regulated in many cancers, including CRC (29). In our study, we found a significant down-regulation of let-7c in the CRC tissue compared to the adjacent non-tumour tissue, which is in agreement with Han et al.; whose study also shows correlation with poor survival (30). In the study by Cappuzzo et al., let-7c down-regulation was associated with a shorter OS but not with a shorter PFS or DCR in mCRC patients treated with anti-EGFR mAbs (23). Even though we did not observe a significant correlation with survival - a fact that could be attributed to the limited patient cohort, we found a significantly lower DCR for patients with let-7c downregulation in our study.

MiR-99a participates in the regulation of epithelial-tomesenchymal transition (EMT), which has been recognised as one of the key cancer-related processes (31). MiR-99a has been demonstrated as a tumour suppressor in a variety of cancers, and miR-99a down-regulation in CRC has previously been reported (32). Moreover, the conclusions of a retrospective study including $78 \mathrm{mCRC}$ patients have suggested that miR-99a dysregulation could be a predictor of a patient's response to chemotherapy (33). Nevertheless, in our study the survival, ORR or DCR, of the mCRC patients treated with chemotherapy combined with antiEGFR mAbs showed no association with miR-99a expression.

MiR-17 is a member of the miR-17-92 cluster, which expresses six miR precursors and plays an important role in carcinogenesis (34). In CRC, it is mainly involved in the regulation of EMT and proliferation via targeting CYP7B1 and SIK 1 genes, respectively $(35,36)$. Additionally, several other potential target genes for miR-17 have been suggested (36). In the present study, we demonstrated a significant miR-17 up-regulation in the tumour in comparison with adjacent non-tumour tissue, which is consistent with the findings of Huang et al. and Lai et al. (36, 37). It has, furthermore, been suggested that miR-17 up-regulation is associated with poor prognosis of cancer patients in a metaanalysis conducted by Huang et al. (38). Even though it has been reported that miR-17 up-regulation is associated with a short OS in CRC patients, the data from patients with metastatic stage treated with systemic therapies are limited and its prognostic or predictive role within this group remains unclear. We observed a correlation of DCR with miR-17 down-regulation. The difference however, was on the edge of statistical significance, and was marginally statistically significant. We did not find any significant difference in PFS or OS that was associated with miR-17 dysregulation.

MiR-143 and miR-145 form a cluster that plays a role in the regulation of multiple cell processes such as proliferation, apoptosis, invasion, differentiation and angiogenesis (39). These miRs are able to suppress cancer progression by targeting numerous oncogenes, indicating 
that they have a tumour-suppressive role (39). Although the down-regulation of the miR-143/miR-145 cluster has been described in several cancer types, inconsistent results have been reported in CRC (40-44). We did not find any significant dysregulations in miR-143 or miR-145, nor in the whole miR-143/miR-145 cluster, when tumour tissue was compared with adjacent non-tumour tissue. Thus, we did not confirm the results of several previously reported studies with limited sample sizes (40-43). Our results are nevertheless in line with those obtained from a large cohort of CRC clinical specimens studied by Schetter et al. (44). Furthermore, the data on the prognostic or predictive role of these miRs are conflicting. Drebber et al. reported that patients with advanced rectal cancer and a low posttherapeutic expression of miR-145 had a significantly worse response to neoadjuvant chemo-radiotherapy (45); similarly, Zhang et al. observed serum miR-145 as one of the 17 miRs predicting chemosensitivity in CRC patients (46). On the other hand, Schee et al. did not find any significant associations between miR-145 dysregulation and metastasis-free or overall survival (47). The results of our study show no significant association of outcome with the dysregulations of miR-143, miR-145, or the whole miR143/miR-145 cluster.

The principal limitations of the present study are its retrospective design and the limited number of patients included, introducing a possible bias caused by the interindividual differences in various clinical parameters. Therefore, the results for PFS and OS were limited and the statistically significant difference was revealed only after optimization of the threshold, as mentioned above. Thus, we mainly focussed on the analysis of ORR and DCR, which allowed us to compare responders and non-responders. The present study furthermore lacked a control cohort not treated with anti-EGFR mAbs, and, therefore, whether the observed miR dysregulations may be a predictive factor exclusively for anti-EGFR-based targeted therapy cannot be concluded with certainty. This issue should be addressed in a future prospective randomised clinical trial. Nevertheless, this is the first study focusing on the role of selected miRs including miR-125b, let-7c, miR-99a, miR-17, miR-143 and miR-145 in $\mathrm{mCRC}$ patients treated with anti-EGFR mAbs.

In conclusion, the results of the present retrospective study show that the up-regulation of miR-125b and let-7c and the down-regulation of miR-17 are associated with good response to the combination of anti-EGFR mAbs and chemotherapy as a first- or second-line therapy. Our data suggest that these three miRs may serve as promising predictive biomarkers. We have not demonstrated an association between the dysregulation of miR-99a, miR-143 and miR-145 and patients' outcome. A future prospective study with a large patient cohort should be conducted in order to confirm these results.

\section{Conflicts of Interest}

OF received honoraria from Roche, GSK and Pfizer for consultations and lectures unrelated to this project. JF has received honoraria from Astra Zeneca, Roche and Novartis for consultations and lectures unrelated to this project. OS, PH, VL, OV, JB, RK, OT, $\mathrm{DM}$ and PP declare that they have no actual or potential conflict of interest including any financial, personal or other relationships with other people or organizations that could inappropriately influence this work.

\section{Authors' Contributions}

OF designed the study and wrote the manuscript with support from OS, PH, VL, JB, OV, RK, OT, JF, DM and PP. VL, OV and JB collected tissue samples. PP and DM performed laboratory analyses. $\mathrm{PH}$ performed statistical analyses.

\section{Acknowledgements}

The Authors would like to thank all patients voluntarily taking part in the study. This study was supported by the project "Center of Clinical and Experimental Liver Surgery", UNCE/MED/006, by the National Sustainability Program I (NPU I) Nr. LO1503 provided by the Ministry of Education Youth and Sports of the Czech Republic and by the Charles University Research Fund (Progres Q39), by the European Regional Development Fund-Project „Application of Modern Technologies in Medicine and Industry" (No. CZ.02.1.01/0.0/0.0/17_048/0007280), by the Ministry of Health, Czech Republic - conceptual development of research organization (University Hospital in Pilsen - FNPl, 00669806). and by the European Union's Horizon 2020 research and innovation programme under grant agreement $\mathrm{N}^{\mathrm{o}} 856620$.

\section{Availability of Data and Materials}

The datasets generated and/or analyzed during the current study are not publicly available due to patient data security but are available from the corresponding author on reasonable request.

\section{References}

1 Jemal A, Bray F, Center MM, Ferlay J, Ward E and Forman D: Global cancer statistics. CA Cancer J Clin 61(2): 69-90, 2011. PMID: 21296855. DOI: 10.3322/caac.20107

2 Lièvre A, Bachet JB, Le Corre D, Boige V, Landi B, Emile JF, Côté JF, Tomasic G, Penna C, Ducreux M, Rougier P, PenaultLlorca $\mathrm{F}$ and Laurent-Puig P: KRAS mutation status is predictive of response to cetuximab therapy in colorectal cancer. Cancer Res 66(8): 3992-3995, 2006. PMID: 16618717. DOI: 10.1158/0008-5472.CAN-06-0191

3 Karapetis CS, Khambata-Ford S, Jonker DJ, O'Callaghan CJ, Tu D, Tebbutt NC, Simes RJ, Chalchal H, Shapiro JD, Robitaille S, Price TJ, Shepherd L, Au HJ, Langer C, Moore MJ and Zalcberg JR: K-ras mutations and benefit from cetuximab in advanced colorectal cancer. N Engl J Med 359(17): 1757-1765, 2008. PMID: 18946061. DOI: 10.1056/NEJMoa0804385

4 Amado RG, Wolf M, Peeters M, Van Cutsem E, Siena S, Freeman DJ, Juan T, Sikorski R, Suggs S, Radinsky R, Patterson 
SD and Chang DD: Wild-type KRAS is required for panitumumab efficacy in patients with metastatic colorectal cancer. J Clin Oncol 26(10): 1626-1634, 2008 PMID: 18316791. DOI: $10.1200 / \mathrm{JCO} .2007 .14 .7116$

5 Lièvre A, Bachet JB, Boige V, Cayre A, Le Corre D, Buc E, Ychou M, Bouché O, Landi B, Louvet C, André T, Bibeau F, Diebold MD, Rougier P, Ducreux M, Tomasic G, Emile JF, Penault-Llorca F and Laurent-Puig P: KRAS mutations as an independent prognostic factor in patients with advanced colorectal cancer treated with cetuximab. J Clin Oncol 26(3): 374-379, 2008. PMID: 18202412. DOI: 10.1200/JCO.2007.12.5906

6 Irahara N, Baba Y, Nosho K, Shima K, Yan L, Dias-Santagata D, Iafrate AJ, Fuchs CS, Haigis KM and Ogino S: NRAS mutations are rare in colorectal cancer. Diagn Mol Pathol 19(3): 157-163, 2010. PMID: 20736745. DOI: 10.1097/PDM. 0b013e3181c93fd1

7 Vaughn CP, Zobell SD, Furtado LV, Baker CL and Samowitz WS: Frequency of KRAS, BRAF, and NRAS mutations in colorectal cancer. Genes Chromosomes Cancer 50(5): 307-312, 2011. PMID: 21305640. DOI: 10.1002/gcc.20854

8 Douillard JY, Oliner KS, Siena S, Tabernero J, Burkes R, Barugel M, Humblet Y, Bodoky G, Cunningham D, Jassem J, Rivera F, Kocákova I, Ruff P, Błasińska-Morawiec M, Šmakal M, Canon JL, Rother M, Williams R, Rong A, Wiezorek J, Sidhu R and Patterson SD: Panitumumab-FOLFOX4 treatment and RAS mutations in colorectal cancer. N Engl J Med 369(11): 1023-1034, 2013. PMID: 24024839. DOI: 10.1056/NEJMoa 1305275

9 Sorich MJ, Wiese MD, Rowland A, Kichenadasse G, McKinnon RA and Karapetis CS: Extended RAS mutations and anti-EGFR monoclonal antibody survival benefit in metastatic colorectal cancer: a meta-analysis of randomized, controlled trials. Ann Oncol 26(1): 13-21, 2015. PMID: 25115304. DOI: 10.1093/annonc/mdu378

10 Bartel DP: MicroRNAs: genomics, biogenesis, mechanism, and function. Cell 116(2): 281-297, 2004. PMID: 14744438. DOI: 10.1016/s0092-8674(04)00045-5

11 Therasse P, Arbuck SG, Eisenhauer EA, Wanders J, Kaplan RS, Rubinstein L, Verweij J, Van Glabbeke M, van Oosterom AT, Christian MC and Gwyther SG: New guidelines to evaluate the response to treatment in solid tumors. European Organization for Research and Treatment of Cancer, National Cancer Institute of the United States, National Cancer Institute of Canada. J Natl Cancer Inst 92(3): 205-216, 2000. PMID: 10655437. DOI: 10.1093/jnci/92.3.205

12 Fiala O, Pitule P, Hosek P, Liska V, Sorejs O, Bruha J, Vycital O, Buchler T, Poprach A, Topolcan O and Finek J: The association of miR-126-3p, miR-126-5p and miR-664-3p expression profiles with outcomes of patients with metastatic colorectal cancer treated with bevacizumab. Tumour Biol 39(7): 1010428317709283, 2017. PMID: 28714375. DOI: 10.1177/1010428317709283

13 Fabian MR, Sonenberg N and Filipowicz W: Regulation of mRNA translation and stability by microRNAs. Annu Rev Biochem 79: 351-379, 2010. PMID: 20533884. DOI: 10.1146/ annurev-biochem-060308-103103

14 Esquela-Kerscher A and Slack FJ: Oncomirs - microRNAs with a role in cancer. Nat Rev Cancer 6(4): 259-269, 2006. PMID: 16557279. DOI: $10.1038 / \mathrm{nrc} 1840$

15 Weidle UH, Schmid D, Birzele F and Brinkmann U: MicroRNAs involved in metastasis of hepatocellular carcinoma: Target candidates, functionality and efficacy in animal models and prognostic relevance. Cancer Genomics Proteomics 17(1): 1-21, 2020. PMID: 31882547. DOI: 10.21873/cgp.20163

16 Weidle UH, Birzele F and Nopora A: Pancreatic ductal adenocarcinoma: MicroRNAs affecting tumor growth and metastasis in preclinical in vivo models. Cancer Genomics Proteomics 16(6): 451-464, 2019. PMID: 31659100. DOI: $10.21873 / \mathrm{cgp} .20149$

17 Weidle UH, Birzele F and Nopora A: MicroRNAs as potential targets for therapeutic intervention with metastasis of non-small cell lung cancer. Cancer Genomics Proteomics 16(2): 99-119, 2019. PMID: 30850362. DOI: $10.21873 / \mathrm{cgp} .20116$

18 Wang Y, Zeng G and Jiang Y: The Emerging Roles of miR-125b in Cancers. Cancer Manag Res 12: 1079-1088, 2020. PMID: 32104088. DOI: $10.2147 /$ CMAR.S232388

19 Banzhaf-Strathmann J and Edbauer D: Good guy or bad guy: the opposing roles of microRNA 125b in cancer. Cell Commun Signal 12: 30, 2014. PMID: 24774301. DOI: 10.1186/1478-811X-12-30

20 Le MT, Shyh-Chang N, Khaw SL, Chin L, Teh C, Tay J, O'Day E, Korzh V, Yang H, Lal A, Lieberman J, Lodish HF and Lim B: Conserved regulation of $\mathrm{p} 53$ network dosage by microRNA$125 \mathrm{~b}$ occurs through evolving miRNA-target gene pairs. PLoS Genet 7(9): e1002242, 2011. PMID: 21935352. DOI: 10.1371/journal.pgen.1002242

21 Scott GK, Goga A, Bhaumik D, Berger CE, Sullivan CS and Benz CC: Coordinate suppression of ERBB2 and ERBB3 by enforced expression of micro-RNA miR-125a or miR-125b. J Biol Chem 282(2): 1479-1486, 2007. PMID: 17110380. DOI: 10.1074/jbc.M609383200

$22 \mathrm{Chen} \mathrm{H}$ and $\mathrm{Xu} \mathrm{Z}$ : Hypermethylation-Associated Silencing of miR-125a and miR-125b: A Potential Marker in Colorectal Cancer. Dis Markers 2015: 345080, 2015. PMID: 26693202. DOI: $10.1155 / 2015 / 345080$

23 Cappuzzo F, Sacconi A, Landi L, Ludovini V, Biagioni F, D’Incecco A, Capodanno A, Salvini J, Corgna E, Cupini S, Barbara C, Fontanini G, Crinò L and Blandino G: MicroRNA signature in metastatic colorectal cancer patients treated with anti-EGFR monoclonal antibodies. Clin Colorectal Cancer 13(1): 37-45.e4, 2014. PMID: 24503111. DOI: 10.1016/j.clcc.2013.11.006

24 Ruby JG, Jan C, Player C, Axtell MJ, Lee W, Nusbaum C, Ge $\mathrm{H}$ and Bartel DP: Large-scale sequencing reveals 21U-RNAs and additional microRNAs and endogenous siRNAs in C. elegans. Cell 127(6): 1193-1207, 2006. PMID: 17174894. DOI: 10.1016/j.cell.2006.10.040

25 Boyerinas B, Park SM, Hau A, Murmann AE and Peter ME: The role of let-7 in cell differentiation and cancer. Endocr Relat Cancer 17(1): F19-F36, 2010. PMID: 19779035. DOI: 10.1677/ERC-090184

26 Johnson SM, Grosshans H, Shingara J, Byrom M, Jarvis R, Cheng A, Labourier E, Reinert KL, Brown D and Slack FJ: RAS is regulated by the let-7 microRNA family. Cell 120(5): 635-647, 2005. PMID: 15766527. DOI: 10.1016/j.cell.2005.01.014

27 Jung HJ and Suh Y: Regulation of IGF -1 signaling by microRNAs. Front Genet 5: 472, 2015. PMID: 25628647. DOI: 10.3389/fgene. 2014.00472

28 Zhang K, Gao H, Wu X, Wang J, Zhou W, Sun G, Wang J, Wang Y, Mu B, Kim C, Chu P, Ho DM, Ann DK, Wong TT and Yen Y: Frequent overexpression of HMGA2 in human atypical teratoid/rhabdoid tumor and its correlation with let-7a3/let-7b miRNA. Clin Cancer Res 20(5): 1179-1189, 2014. PMID: 24423609. DOI: $10.1158 / 1078-0432 . C C R-13-1452$ 
29 Mizuno R, Kawada K and Sakai Y: The molecular basis and therapeutic potential of Let-7 microRNAs against colorectal cancer. Can J Gastroenterol Hepatol 2018: 5769591, 2018. PMID: 30018946. DOI: 10.1155/2018/5769591

30 Han HB, Gu J, Zuo HJ, Chen ZG, Zhao W, Li M, Ji DB, Lu YY and Zhang ZQ: Let-7c functions as a metastasis suppressor by targeting MMP11 and PBX3 in colorectal cancer. J Pathol 226(3): 544-555, 2012. PMID: 21984339. DOI: 10.1002/path.3014

31 Mei LL, Qiu YT, Huang MB, Wang WJ, Bai J and Shi ZZ: MiR99a suppresses proliferation, migration and invasion of esophageal squamous cell carcinoma cells through inhibiting the IGF1R signaling pathway. Cancer Biomark 20(4): 527-537, 2017. PMID: 28800315. DOI: $10.3233 / \mathrm{CBM}-170345$

32 Zhu P, Liu J, Lu M, Wu G, Lin X, Cai L and Zhang X: Influence and mechanism of miR-99a suppressing development of colorectal cancer (CRC) with diabetes mellitus (DM). Onco Targets Ther 12: 10311-10321, 2019. PMID: 31819515. DOI: 10.2147/OTT.S190998

33 Molina-Pinelo S, Carnero A, Rivera F, Estevez-Garcia P, Bozada JM, Limon ML, Benavent M, Gomez J, Pastor MD, Chaves M, Suarez R, Paz-Ares L, de la Portilla F, Carranza-Carranza A, Sevilla I, Vicioso L and Garcia-Carbonero R: MiR-107 and miR99a-3p predict chemotherapy response in patients with advanced colorectal cancer. BMC Cancer 14: 656, 2014. PMID: 25197016. DOI: $10.1186 / 1471-2407-14-656$

34 Fang LL, Wang XH, Sun BF, Zhang XD, Zhu XH, Yu ZJ and Luo $\mathrm{H}$ : Expression, regulation and mechanism of action of the miR-1792 cluster in tumor cells (Review). Int J Mol Med 40(6): 16241630, 2017. PMID: 29039606. DOI: 10.3892/ijmm.2017.3164

35 Xi XP, Zhuang J, Teng MJ, Xia LJ, Yang MY, Liu QG and Chen JB: MicroRNA-17 induces epithelial-mesenchymal transition consistent with the cancer stem cell phenotype by regulating CYP7B1 expression in colon cancer. Int J Mol Med 38(2): 499506. 2016. PMID: 27278684. DOI: 10.3892/ijmm.2016.2624

36 Huang C, Liu J, Xu L, Hu W, Wang J, Wang M and Yao X: MicroRNA-17 promotes cell proliferation and migration in human colorectal cancer by downregulating SIK1. Cancer Manag Res 11: 3521-3534, 2019. PMID: 31118777. DOI: 10.2147/CMAR.S191087

37 Lai H, Zhang J, Zuo H, Liu H, Xu J, Feng Y, Lin Y and Mo X: Overexpression of miR-17 is correlated with liver metastasis in colorectal cancer. Medicine (Baltimore) 99(9): e19265, 2020. PMID: 32118734. DOI: 10.1097/MD.0000000000019265

38 Huang C, Yu M and Yao X: MicroRNA-17 and the prognosis of human carcinomas: a systematic review and meta-analysis. BMJ Open 8(5): e018070, 2018. PMID: 29858404. DOI: 10.1136/bmjopen-2017-018070

39 Cui SY, Wang R and Chen LB: MicroRNA-145: a potent tumour suppressor that regulates multiple cellular pathways. J Cell Mol Med 18(10): 1913-1926, 2014. PMID: 25124875. DOI: 10.1111/ jcmm.12358
40 Bandrés E, Cubedo E, Agirre X, Malumbres R, Zárate R, Ramirez N, Abajo A, Navarro A, Moreno I, Monzó M and García-Foncillas J: Identification by Real-time PCR of 13 mature microRNAs differentially expressed in colorectal cancer and non-tumoral tissues. Mol Cancer 5: 29, 2006. PMID: 16854228. DOI: $10.1186 / 1476-4598-5-29$

41 Cummins JM, He Y, Leary RJ, Pagliarini R, Diaz LA Jr, Sjoblom T, Barad O, Bentwich Z, Szafranska AE, Labourier E, Raymond CK, Roberts BS, Juhl H, Kinzler KW, Vogelstein B and Velculescu VE: The colorectal microRNAome. Proc Natl Acad Sci U S A 103(10): 3687-3692, 2006. PMID: 16505370. DOI: 10.1073/pnas.0511155103

42 Michael MZ, O' Connor SM, van Holst Pellekaan NG, Young GP and James RJ: Reduced accumulation of specific microRNAs in colorectal neoplasia. Mol Cancer Res 1(12): 882-991, 2003. PMID: 14573789.

43 Arndt GM, Dossey L, Cullen LM, Lai A, Druker R, Eisbacher M, Zhang C, Tran N, Fan H, Retzlaff K, Bittner A and Raponi M: Characterization of global microRNA expression reveals oncogenic potential of miR-145 in metastatic colorectal cancer. BMC Cancer 9: 374, 2009. PMID: 19843336. DOI: 10.1186/1471-2407-9-374

44 Schetter AJ, Leung SY, Sohn JJ, Zanetti KA, Bowman ED, Yanaihara N, Yuen ST, Chan TL, Kwong DL, Au GK, Liu CG, Calin GA, Croce CM and Harris CC: MicroRNA expression profiles associated with prognosis and therapeutic outcome in colon adenocarcinoma. JAMA 299(4): 425-436, 2008. PMID: 18230780. DOI: $10.1001 /$ jama.299.4.4

45 Drebber U, Lay M, Wedemeyer I, Vallböhmer D, Bollschweiler E, Brabender J, Mönig SP, Hölscher AH, Dienes HP and Odenthal M: Altered levels of the onco-microRNA 21 and the tumor-supressor microRNAs 143 and 145 in advanced rectal cancer indicate successful neoadjuvant chemoradiotherapy. Int J Oncol 39(2): 409415, 2011. PMID: 21567082. DOI: 10.3892/ijo.2011.1036

46 Zhang J, Zhang K, Bi M, Jiao X, Zhang D and Dong Q: Circulating microRNA expressions in colorectal cancer as predictors of response to chemotherapy. Anticancer Drugs 25(3): 346-352, 2014. PMID: 24304648. DOI: 10.1097/CAD.0000000 000000049

47 Schee K, Boye K, Abrahamsen TW, Fodstad $\varnothing$ and Flatmark K: Clinical relevance of microRNA miR-21, miR-31, miR-92a, miR-101, miR-106a and miR-145 in colorectal cancer. BMC Cancer 12: 505, 2012. PMID: 23121918. DOI: 10.1186/14712407-12-505

Received May 31, 2020

Revised June 21, 2020

Accepted June 23, 2020 